\title{
FRAY ALONSO DE JESÚS Y ORTEGA: RELACIONES TRANSATLÁNTICAS DE MECENAZGO, ARTE Y PODER EN LA GRANADA BARROCA
}

\section{FRAY ALONSO DE JESÚS Y ORTEGA: TRANSATLANTIC RELATIONSHIPS OF PATRONAGE, ART AND POWER IN THE BAROQUE GRANADA}

\author{
Adrián Contreras-Guerrero \\ Universidad Complutense de Madrid. España \\ ORCID: 0000-0001-9391-5469 \\ a.contreras@ucm.es
}

\begin{abstract}
Con la culminación de la iglesia de San Juan de Dios de Granada, fray Alonso de Jesús y Ortega demostraba su gran capacidad de gestión al tiempo que dignificaba un espacio muy simbólico para los frailes juaninos: la casa matriz de la Orden Hospitalaria y el lugar de reposo de su santo patriarca. Los objetivos de este trabajo son dar a conocer las estrategias seguidas por el Padre Ortega para financiar tan magna obra así como completar el perfil biográfico de este encumbrado personaje que gobernó con mano firme los destinos de la Orden Hospitalaria durante más de treinta y seis años. En dicha tarea nos detendremos a explorar un aspecto obviado por la historiografía: la decisiva aportación de los virreinatos americanos.

Palabras clave: Orden Hospitalaria; mecenazgo; Virgen de Guadalupe; Galeón de Manila; porcelana china.
\end{abstract}

With the culmination of the Church of Saint John of God in Granada, Fray Alonso de Jesús y Ortega demonstrated his great capacity for management while dignifying a very symbolic space for the Juaninos friars: the founding house of the Hospitaller Order and the resting place of the remains of his holy patriarch. The objectives of this work are to raise awareness about the strategies followed by Father Ortega to finance such a great temple as well as complete the biographical profile of this lofty personage who governed with firm hand the destinies of the Hospitaller Order for more tan thirty-six years. In this task we will stop to explore an aspect overlooked by historiography: the decisive contribution of the American Viceroyalties. celain.

Keywords: Hospitaller Order; patronage; Virgin of Guadalupe; Manila Galleon; Chinese por- 


\section{EL PROTAGONISTA: SEMBLANZA BIOGRÁFICA}

Fray Alonso de Jesús y Ortega nació en Lucena el 14 de marzo de 1696 en el seno de una familia de distinguida prosapia, siendo su madre doña María Ángela de Ortega y su padre don Juan Matías Pardo y Toro. Fue bautizado el 27 de marzo del mismo año bajo el padrinazgo de don Pedro Llano de Zamora, alguacil mayor de la ciudad. Cuando solo contaba tres años pasó a Sevilla a vivir con su tío materno, don Gabriel de Ortega, "por lo que dicen que tomó su nombre". Su infancia estuvo marcada por multitud de enfermedades, lo que le llevó, según sus panegiristas, a ingresar en la Orden Hospitalaria con 14 años (1710). Profesó en el convento-hospital de Nuestra Señora de la Paz de Sevilla en 1713, ocupándose de la atención de los enfermos en los hospitales de Lucena, Úbeda, Mérida y Sanlúcar de Barrameda. En 1731 el rey Felipe V por medio de sus ministros puso en sus manos la superintendencia de los hospitales militares de Alcántara, Albuquerque, Ciudad Rodrigo, Zamora y Puebla de Sanabria, obteniendo por su gestión un cierto reconocimiento ${ }^{2}$. En 1731 comenzó su ascenso meteórico dentro de la orden ocupando en un primer momento las prelacías de Priego y Sevilla, y en 1733 los puestos de secretario general de la orden, provincial y prior del convento de Granada, todo de forma simultánea. Por muerte del entonces general don Rodrigo Jerónimo Venegas (24-12-1735), fue elegido vicario, y tres años después, general en propiedad del cargo. Cumplido el tiempo de su mandato renovó en 1747, y, estando prohibido por las Constituciones Apostólicas ocupar dicho puesto en más de dos ocasiones, fue necesario un Breve papal ${ }^{3}$ que autorizara su continuidad en 1757. Sobre este episodio nos dicen los cronistas ${ }^{4}$ que fray Alonso estaba deseoso de que llegara el capítulo general de donde saldría su sustituto pues su deseo era retirarse, y que, siendo de nuevo elegido, pidió de rodillas y con lágrimas en los ojos que se le eximiera de dicha responsabilidad. Tal era el talante barroco de nuestro protagonista. Su cursus honorum se completó con su nombramiento como ministro titular del Santo Oficio de Córdoba el 28 de enero de 1737, y posteriormente de los de Madrid y Granada. Murió siendo general perpetuo de la Orden

${ }^{1}$ SOTELO, Fray Francisco: El Zorobadel amplificado, y amplificador, de la Religion, $y$ del Instituto, de la Santa Hospitalidad. Oracion funebre, que en las honras celebradas por este religiosisimo convento Hospital de Señor San Juan de Dios de la Ciudad de Granada: Al Rmo. P. Fr. Alonso de Jesus y Ortega... Granada, 1772, s. p.

2 Ibidem.

${ }^{3}$ Nos referimos al Breve pontificio Exponi Nobis de 7 de febrero de 1757. Asimismo el 4 de julio de 1757 Benedicto XIV aprobaba las actas capitulares de su renovación.

${ }^{4}$ PARRA Y COTE, Fray Alonso: Desempeño el mas honroso de la obligacion mas fina, y relacion historico-panegyrica de las Fiestas de dedicacion del magnifico templo de la Purma. Concepcion de Nuestra Señora, del Sagrado Orden de Hospitalidad de N. P. San Juan de Dios de la nobilissima, e ilustre, siempre fiel ciudad de Granada. Madrid, 1759, p. 274. 
Hospitalaria en 1771 y su cuerpo recibió sepultura en el templo de sus desvelos, para lo que también fue necesaria una dispensa papal por estar prohibido el enterramiento Intra Ecclesiam.

A su mérito como mecenas de las artes se añadió el haber editado varios libros que son de un enorme interés histórico. Los títulos más destacados son Adiciones a las Constituciones de la Orden (Madrid, 1744), la impresión del Bulario en dos tomos a cargo de fray Alonso Parra y Cote (Madrid 1756), el Libro de las fiestas de dedicación del nuevo templo de Granada del mismo autor (Madrid, 1759), la Historia de la Provincia de Filipinas del Padre Manuel Maldonado de Puga (Manila, 1742), la Instrucción de Novicios del Padre Victoria (Madrid, 1749) y más de setenta circulares para la edificación de las comunidades conventuales. Su fama fue cantada por varios panegiristas entre los que destaca fray Francisco Sotelo, quien recogió algunos testimonios que de su vida dieron algunos personajes ilustres del momento. De entre ellos extraemos el del licenciado Bernabé Antonio de la Peña: "Siempre fue conocido en España, y aún fuera de ella este Rvdmo General, por uno de los Grandes, que han gobernado la Religión, como lo publica el sumo aprecio, y concepto, que de sus prendas y conducta había formado el Señor Benedicto XIV, para habilitarle en General perpetuo, y vitalicio de su Orden"5. En la misma línea, fray Bartolomé de la Peña dice que "la estimacion, y credito, que su Rma. tiene, y lo mucho que todas las Personas de autoridad, y de todos estados, y clases en esta Ciudad hazen de su Persona, siendo tan publico, tengo por de mas referirlo, lo qual redunda en credito de la Religion, y en útil de los Conventos"6.

Por todo ello fue conocido con el sobrenombre de "El Magno". Su generalato representa uno de los momentos dorados de la Orden Hospitalaria en España, a cuya muerte sobrevino una paulatina decadencia que desembocó en la exclaustración de 1835.

${ }^{5}$ SOTELO, Fray Francisco: El Zorobadel amplificado..., op. cit., s. p.

${ }^{6}$ DE LA PEÑA, Bartolomé: Certificación dada por el R. P. Fr. Bartholome de la Peña, Definidor, y Secretario General de la Religion de N. P. S. Juan de Dios, de los gastos, que N. $R^{m o}$ P. General Fr. Alonso de Jesus y Ortega, ha tenido, y pagado en las obras de Enfermeria, y otras del Convento de Granada, y Limosnas dadas à los demás de estas Provincias... Granada, 1746, p. 50. La certificación del hermano fray Bartolomé de la Peña fue impresa en Granada el 15 de septiembre de 1746, justo cuando mediaban las obras de la iglesia de San Juan de Dios, y estuvo perdida durante mucho tiempo hasta que se encontró un ejemplar de la misma en la Biblioteca Ricardo B. Anaya de San Luis Potosí (México). En este valioso documento se detalla minuciosamente el proceso constructivo del edificio, por lo que nos referiremos a él en reiteradas ocasiones. 


\section{EL TEMPLO DE SAN JUAN DE DIOS Y SU FINANCIACIÓN AMERICANA}

Fray Alonso de Jesús y Ortega eligió la iglesia hospitalaria de Granada como telón de fondo de su retrato oficial, pintado por Diego Sánchez Sarabia en 1758 (Figura 1). Un año después, la misma escenografía se repitió en el grabado que encargó a Andrade, donde aparece ofreciendo los escritos que patrocinó a San Juan de Dios. Ambas obras son un buen testimonio del orgullo que sentía como promotor del edificio. Para levantar desde sus cimientos aquella inconmensurable obra barroca, llevándola a término en el tiempo récord de 25 años (1734-1759), se sirvió de una calculada estrategia de financiación (Figura 2). Para empezar contaba con cierto patrimonio propio proveniente de la herencia familiar, siendo constantes sus limosnas en las cuentas de gasto. Su compromiso personal con el proyecto fue total, llegando a vender sus propios bienes cuando la insuficiencia de fondos amenazaba con paralizar las obras, algo que ocurrió en varias ocasiones ${ }^{7}$. Estas generosas dádivas se sumaron al dinero proveniente de la caja central de la orden, que sin bien era un recurso habitual para la erección de nuevas fundaciones, en esta ocasión fue más generoso de lo habitual. Así, algunos ingresos con los que contaba la orden fueron aplicados exclusivamente a los gastos de fábrica, como por ejemplo el rendimiento obtenido del "juro de Montazgos, y los granos que diessen los Cortijos del Berbe, para que se convirtiesse uno, y otro en beneficio de dicha obra"s.

Junto a estos recursos propios, razonable forma de predicar con el ejemplo, otro de los grandes méritos de fray Alonso fue la captación de recursos externos. En los libros de cuentas son muy frecuentes los donativos obtenidos por el carismático general "de sus amigos" . Otra forma de contar siempre con los recursos necesarios, especialmente en momentos de carestía, fue la solicitud de diferentes préstamos que iban siendo amortizados según la disponibilidad económica ${ }^{10}$. Por

${ }^{7}$ Fray Bartolomé de la Peña lo anota así: "Mas, tiene su Rma. en el expressado año dados, y aplicados para la Obra de la nueva Iglesia de este Convento de Granada veinte y un mil setecientos cincuenta reales, y siete mrs. que pertenecen à dicho nuestro Reverendisimo, procedidos de la ropa, y alhajas, que de suso se rifaron, y los diò a esta Santa Casa". DE LA PEÑA, Bartolomé: Certificación..., op. cit., p. 17.

${ }^{8}$ Según acordaron los hermanos reunidos en la junta de comunidad celebrada el día 15 de enero de 1738. DE LA PEÑA, Bartolomé: Certificación..., op. cit., p. 31.

${ }^{9}$ Entre los numerosos ejemplos que podemos nombrar, citamos las dos casas de la localidad de Alhama "que donò un devoto à este Hospital, con quien su Rma. tenia mucha inclusion. DE LA PEÑA, Bartolomé: Certificación..., op. cit., p. 12.

10 "Se tomaron à censo cien mil reales vellon, en continuacion de lo determinado por la Religion, para que prosiguiesse la Obra de la Iglesia de nuestro Convento de Granada, los que diò Don Francisco de Sexma, Presbytero, y se cargaron sobre los bienes de dicho Convento". DE LA PEÑA, Bartolomé: Certificación..., op. cit., p. 26. 
último, dentro de este incipiente mercado bancario e inmobiliario del siglo XVIII, otra interesante fuente de ingresos estuvo en el alquiler de viviendas. La erección del nuevo edificio había implicado la demolición de una casa que la orden tenía alquilada en el solar, lo que fray Alonso solucionó comprando un edificio de similares características ubicado en la calle de Gracia. Pero no contento con suplir esta pérdida, aprovechó la cuadrilla de albañiles que estaba trabajando en el templo para que "labrassen tres casas à toda costa" en los "dos sitios que quedaban perdidos à los lados de la Portada; y eran inútiles à el Convento [...] haciendo fachada con la misma Portada, que le sirve de la mejor hermosura" ${ }^{11}$. Es decir, compuso una línea de fachadas hacia la calle donde la imponente portada del nuevo templo quedaba arropada por un buen marco arquitectónico que además producía 1.440 reales de alquiler al año.

Pero hablemos ahora del dinero americano. Gracias a una Real Cédula de Felipe $\mathrm{V}$ que lo autorizaba, los frailes hospitalarios pudieron recoger limosnas en los virreinatos americanos para su aplicación en la fábrica de Granada ${ }^{12}$. La dependencia que se tuvo de estos envíos llegó a ser tan grande que su no concurrencia ocasionaba graves contratiempos. En cierta ocasión, con motivo de las disputas que el rey Felipe $\mathrm{V}$ mantuvo con los ingleses, el tráfico marítimo con las Indias quedó suspendido y los fondos recaudados fueron retenidos en los puertos americanos. En dichas circunstancias fray Alonso se vio obligado a solicitar un nuevo préstamo no previsto al marqués de Casa Pontejos. Así lo expresa fray Bartolomé de la Peña en su Certificación de 1746: "quedarà satisfecho [el préstamo] siempre que el Señor sea servido darnos paz, porque pudiendose traficar los Mares se consigan las Remesas del que està detenido en las Provincias de Indias para este fin, por averle juntado suficientes cantidades en las limosmas, que se han pedido por los Religiosos nombrados en aquellas Provincias para ello, en virtud de las facultades, que se concedieron por su Mag. y Real Consejo de Indias, de que se embiaron los correspondientes Despachos"13.

En efecto, una vez comenzaron a llegar los galeones pudo ser redimido este censo gracias a dos envíos consecutivos, uno en 1749 cuando se enviaba una gran araña de plata desde Nueva España, y otro en 1751 consistente en vasos sagrados y plata provenientes de Argentina ${ }^{14}$. La gran lámpara a la que hemos aludido

${ }^{11}$ Ibidem, pp. 31-32.

${ }_{12}$ No es algo excepcional, sobre la costumbre eclesiástica de recabar dinero en América puede verse el caso contemporáneo de la madre Isabel Moreno Caballero, quién pasó personalmente a México hasta en dos ocasiones para sostener el beaterio de la Trinidad en Sevilla. GONZÁLEZ GÓMEZ, Juan Miguel: "Un ejemplo del mecenazgo americano en Sevilla: El Beaterio de la Trinidad", Laboratorio de Arte, 3, 1990, pp. 97-108.

${ }^{13}$ DE LA PEÑA, Bartolomé: Certificación..., op. cit., p. 42.

${ }^{14}$ ISLA MINGORANCE, Encarnación: José de Bada y Navajas. Arquitecto andaluz (1691-1755). Granada, 1977, p. 379. 
pesaba 146 marcos y fue enviada por el comisario general de Nueva España, fray José Alfonso Mayoral, llegando al puerto de La Graña (Galicia). Si bien la donación estaba dirigida personalmente a fray Alonso, "para su persona, ô para que la mande poner delante del arca de las reliquias de nuestro santo Patriarca en su yglesia de Granada", este quiso consultar el destino que debía dársele a tan rica presea con el definitorio general. La razón de esta consulta estribaba en el carácter sumamente ostentoso de la pieza, lo que podía generar cierta incomodidad entre los granadinos. Así quedó recogido en el acta de aquel día: "pues de dexarla en el convento y ponerla en su yglesia en parte es dar escandalo el convento y ser preziso pedir limosna, y contraer empeños para atender a la manutenzion de pobres, y religiosos siempre que los seglares viesen semexante alhaxa en la yglesia, y que de ella no se nezesita, seria el blanco de todos para retirar las limosnas diciendo que el convento no estaría tan pobre quando tenia en su yglesia una alhaxa tan superior, y sin servir, que se vendiese para remediar el convento, con otras conversaciones que resultarian nada favorables a el credito del abito"15. El acuerdo sobre este asunto fue fundir la lámpara para hacer ocho más pequeñas y así colocarlas en la iglesia con más disimulo.

En el mismo documento se informa de que aún llegarían otras donaciones desde las Indias, tanto en dinero como en especie ${ }^{16}$. Documentos posteriores confirman la llegada masiva de este dinero siendo interesante observar cómo las limosnas de las diferentes casas americanas excedieron ostensiblemente las recogidas en muchos de los conventos de la Península. Así, entre 1734 y 1757 la aportación indiana representaba un $23 \%$ del total de fondos obtenidos ${ }^{17}$, siendo la suma de 421.337 reales aportados por Perú la partida individual más destacada que solo fue superada por la contribución del mismo padre Ortega, quien había dado 476.500 reales de vellón.

Pero estos esfuerzos económicos no resultaron tan desinteresados como pudiera parecer, $\mathrm{y}$, a la postre, acabaron comprometiendo la voluntad del padre Ortega. Así, fueron varias las polémicas internas que sacudieron su mandato, dada "la inamovilidad de los Comisarios Generales, Provinciales y aún Superiores locales; porque ellos le ayudaban eficazmente, con las colectas que hacían en aquellas tierras, a sufragar los cuantiosos gastos que en la construcción de la iglesia de Granada"18. Quizá el testimonio más elocuente al respecto sea el recogido en una

15 AMSJD (Archivo-Museo San Juan de Dios "Casa de los Pisa"), Ar. III, Libro de actas de Definitorios Generales 1750-1767, 18-1-1750, Libro Nuebo donde se sientan Los Difinitorios de la Religion de Nro. Padre San Juan de Dios, ff. 10v-11v.

16 Ibidem, f. $11 \mathrm{r}$.

${ }^{17}$ ADPG (Archivo de la Diputación Provincial de Granada), San Juan de Dios Gobierno, Actas, L07788, 25-5-1758, Libro de Juntas y Capítulos de la Orden, ff. 161v-164v.

${ }^{18}$ GÓMEZ BUENO, Juan Ciudad: Compendio de Historia de la Orden Hospitalaria de San Juan de Dios. Granada, 1963, p. 298. 
carta enviada por don Francisco Vidaurri al virrey Bucareli en 1770: "El P. Gral. pide a los comisarios, los comisarios a los priores, éstos lo sacan de los conventos [...] Por las dádivas, los priores se hacen vitalicios en los conventos o cuando no, no cesan de ser priores, ya de este convento ya del otro, y con esto dan a los comisarios y enriquecen, como hay varios, y entre ellos lo son el P. Pedevilla, que murió, el P. Mota y el P. Betancourt que hoy es presbítero, el P. Cervantes, que murió, el P. Cribas que falleció, pero éste gastó más pompa que un Sr. Oidor. Con las dádivas de los comisarios al dicho General, se hacen vitalicios y despóticos, de tal suerte que no hay más regla ni más constituciones que el arbitrio de los comisarios de este reino" 19 .

En este mismo sentido se manifestó el padre Juan Manuel Maldonado de Puga, prior del convento de Manila y autor de la historia de los hospitalarios en Filipinas. Fueron varias las ocasiones en las que Puga requirió la independencia de las islas con respecto al Comisariado General de Nueva España del que dependían, alegando entre otras razones las malas consecuencias que se derivaban del mantenimiento de prelados en sus cargos. Circunstancialmente, sería en el capítulo general de 1757 cuando se obtendría esta ansiada independencia ${ }^{20}$, toda vez que las obras de la iglesia de Granada tocaban a su fin.

A propósito de las irregularidades imputables al padre Ortega, traemos a colación un misterioso asunto que aún no ha sido resuelto. Siempre se ha creído que la mandíbula de San Juan de Dios se encontraba en Granada junto a los demás restos óseos del santo. Sin embargo, el descubrimiento en Lima de otra mandíbula del santo causó un cierto estupor en 1932 cuando el provincial de España, padre Guillermo Llop, y el general de la orden, padre Faustino Calvo, la encontraron en su visita a la ciudad. La carta que el primero remitió al segundo tras el regreso a España dice así: “¿Cómo puede ser esto?... No sé cual de ellas será apócrifa. Vtra. Paternidad Rvma. dirá si convendría indagar sobre este delicado asunto, pues yo puedo jurar que, en la referida iglesia de Lima, existe la supradicha reliquia y en la Urna de Granada también, como aparece en las fotografías que de las reliquias poseemos y que me permito acompañarle"21. La cuestión

${ }^{19}$ VELASCO CEBALLOS, Rómulo: Visita y reforma de los Hospitales de San Juan de Dios de Nueva España en 1772-1774. Vol. II. México, 1945; y ALBERRO, Solange: Apuntes para la historia de la Orden Hospitalaria de San Juan de Dios, en la Nueva España-México. 1604-2004. México, 2005, p. 279.

${ }^{20}$ AMSJD, Ar. III, 6-5-1757, Libro $3^{\circ}$ Para los Capitulos Generales, y Provinciales que celebra la Religion de N. Pe. S $S^{n}$. Juan de Dios, f. 57r-v.

${ }^{21}$ AMSJD, Hermanos mártires, escritos del Beato Guillermo Llop, Documentación y correspondencia varia [4], Comp. 3, 16-9-1932, Carta del Padre Guillermo Llop al Padre Faustino Calvo al General fray Faustino Calvo, f. 12r. La conservada en este archivo granadino es copia de época sacada con papel de calco, el original se encuentra en el archivo de la orden en Roma y está copiada también en el "Proceso de escritos", v. 9, f. 101r. 
quedó silenciada hasta el año 1995, cuando se abrió la urna de las reliquias coincidiendo con el V centenario del nacimiento de San Juan de Dios. Al reparar en la ausencia de la mandíbula, fray Juan José Hernández Torres, a la sazón rector de la basílica, emprendió una búsqueda que le llevaría a encontrarla en un convento de monjas de la ciudad de Lima. Después se iniciaron los trámites necesarios para su recuperación, siendo custodiada actualmente por los frailes hospitalarios de Lima ${ }^{22}$ (Figura 3). Pero, ¿cómo llegó al Perú? Teniendo en cuenta que las limosnas más generosas vinieron desde aquel virreinato, no sería extraño que la reliquia hubiese llegado allí a modo de contraprestación espiritual por el auxilio prestado. De hecho, el diferente color que presenta la mandíbula de Granada con respecto a los demás huesos del santo conservados en la misma urna parece indicar que esta y no la peruana sería la falsa reliquia, teoría que deberá ser corroborada mediante un análisis científico más exhaustivo. Surgen entonces otras dudas. ¿Por qué se sustituyó la mandíbula en la urna de Granada y no se hizo la donación con carácter oficial? ¿Acaso era un regalo secreto?

Como hemos indicado, el padre Ortega debió sentirse obligado de alguna manera con los colaboradores de su magno proyecto, aunque ello le planteara algunas dudas de tipo moral y quizá en este contexto podamos encuadrar la existencia duplicada de esta reliquia. Estas dudas a veces pueden rastrearse en la documentación, y por poner un ejemplo, al mismo tiempo que se sucedían las denuncias sobre la permanencia de ciertas personas en los puestos de mando, él mismo exponía en el capítulo de 1747 la necesidad de "que el superior empleo [el cargo de general] no se perpetúe en un sujeto". Proponía para ello un proyecto de alternativa en el generalato de forma que el candidato elegido no pudiera pertenecer a la misma provincia del general que cesaba en el puesto ${ }^{23}$. Estas objeciones de conciencia le rondaron en muchas ocasiones durante su vida y por ejemplo otra cosa que le preocupó fue la conveniencia de poseer un coche propio, para cuyo descargo moral tuvo que ser avalado por la junta de definitorio de la orden y por la Sagrada Congregación de Obispos y Regulares ${ }^{24}$. Es la suya, en fin, una personalidad poliédrica propia del momento que le tocó vivir.

22 Agradecemos a Iván Panduro Sáez y a la comunidad hospitalaria de Lima la imagen de la reliquia que acompaña estas líneas.

23 AMSJD, Ar. III, 9-5-1747, Libro de los Capitulos Generales y Provinciales que zelebra la Religion de Nuestro Padre San Juan de Dios, f. 293r-v.

${ }^{24}$ La primera en Madrid en 20 de marzo de 1738 ratificando otros dos dictámenes anteriores, la segunda en 22 de febrero de 1739. DE LA PEÑA, Bartolomé: Certificación..., op. cit., p. 45. 


\section{"QUE EN TIEMPO DE SU REVERENDÍSIMA SE TRAJO DE INDIAS": LOS TESOROS VIAJEROS}

La contribución americana para el nuevo templo granadino no se redujo a lo monetario sino que también llegaron copiosos presentes como la lámpara de plata mexicana y los vasos argentinos que ya hemos señalado. En este apartado estudiaremos varios objetos americanos que enriquecieron el convento y su iglesia.

Entre estos objetos el caso más llamativo es el de la urna de plata que contiene las reliquias de San Juan de Dios, verdadero centro espiritual y simbólico en torno al que se construyó el complejo arquitectónico de la iglesia-camarín. Para contener estos huesos, había enviado fray Francisco Barradas, comisario general de la provincia de Nueva España, una urna de 125 marcos de plata que fue recibida en el puerto de Cádiz a principios de 1730. El general Rodrigo Jerónimo Venegas colocó la urna en la antigua capilla del convento y dentro de ella puso las reliquias, hasta que su sucesor, el padre Ortega, ideó el nuevo edificio y decidió fundirla. Esta pieza novohispana no fue nunca del agrado de fray Alonso y en 1746, cuando la urna estaba aún en su forma y emplazamiento originales, fue objeto de una primera remodelación, siendo añadidas "quatro maceticas de plata en las esquinas, y en ellas se pusieron quatro ramos de flores de Napoles: quatro Serafines con sus remates" ${ }^{25}$. Ocho años más tarde, con la fábrica del templo en estado avanzado, fue cuando el padre Ortega decidió rehacerla por completo porque le parecía que tenía forma de "tumba" y prefería una a la "moda moderna", es decir, en estilo rococó (Figura 4). Lo dicho se comprueba en el inventario de 1758: "Por suplica que hizo la comunidad de este convento de Granada a Nuestro Reverendisimo Padre General para que con la plata de la urna viexa, en que estaban las reliquias de Nro. Santo Patriarcha se hiziesse otra nueba para mayor desencia y hermosura, su fecha $1^{\circ}$ de Jullio de 1754: por acuerdo del Reverendo Difinitorio se desvaratò por don Miguel de Guzman, Maestro de Platero, ya citado, y se pessò en presencia de Su Reverendisima, Reverendos Padres Difinidores; Provincial Conziliar y otros religiosos que concurrieron, y segun la certificazion que de todos consta firmada, y del Maestro con fecha del dicho dia $1^{\circ}$ de Jullio, y tubo el de quinientas zinquenta y seis onzas y diez adarmes de ley de a 20 Reales a cuyo precio importa \#11.132 reales y 17 maravedies" ${ }^{26}$. Como queda demostrado a la luz de esta información archivística, no es verdad, como se ha sostenido, que la urna actual sea la

${ }^{25}$ Ibidem, p. 11.

${ }^{26}$ ADPG, leg. 25, n. 11, 1758, Imbentario de las alaxas de Iglesia, Sachristia, y Camarin que N. Rmo. P. Gral. entregò a este convento de Granada, ff. 17v-18r. 
original mexicana, ni que las adecuaciones hechas a la pieza fueran pocas ${ }^{27}$. La autoría del jienense Miguel de Guzmán queda así reforzada ${ }^{28}$.

Sin embargo, la urna mexicana no fue el único objeto que se rehízo, pues todo el utillaje de plata de la antigua iglesia corrió la misma suerte: siete lámparas, tres cálices, dos copones, ciriales, candelabros, cruz procesional, custodia, vinajeras, incensario, naveta, la diadema del santo y hasta las ocho onzas de plata procedentes de "distintos milagros". Con todo ello se confeccionó el nuevo ajuar del templo según el gusto imperante.

Pero fijemos ahora nuestra atención en otro testigo artístico de esta relación barroca entre Granada y Nueva España. En la subida al camarín de San Juan de Dios, en la tribuna que se asoma sobre el presbiterio del templo, se encuentra hoy un altar abridero de pequeñas dimensiones presidido por el lienzo de la Virgen de Guadalupe de México. Se trata de un mueble que estaba desmontado en un almacén del antiguo hospital sin que se tuviera conocimiento de su procedencia. A raíz de esta investigación se procedió a su recuperación histórica y material, y tras su restauración se colocó en este nuevo emplazamiento ${ }^{29}$. El retablo está compuesto por una mesa de altar con dos puertas que ocultan una cajonera para almacenamiento de ornamentos litúrgicos, y un único cuerpo que remata en arco de medio punto con sendas puertas (Figura 5). No existe certeza documental sobre el autor de esta obra, aunque su análisis estilístico y su cronología no dejan lugar a dudas, ya que presenta las mismas características de quien era a todos los efectos el tallista oficial de la orden en ese momento: Francisco José Guerrero ${ }^{30}$. Recursos propios del artista son la talla vigorosa de sus motivos vegetales, los espejos embutidos en el intradós del arco o los doseletes con bambalinas dotadas de movimiento. Las esculturas que completaban las hornacinas laterales, San Juan de Dios y San Rafael, fueron recuperadas de una vitrina de la iglesia donde se conservaban ajenas al retablo. De forma paralela a lo que ocurre con la labor de ensamblaje, estas piezas se encuadran en la producción del escultor de cámara de fray Alonso, el polifacético artista Diego Sánchez Sarabia.

${ }^{27} \mathrm{http}: / /$ www.afehc-historia-centroamericana.org/?action=fi_aff\&id=1870 (Consultado el 24-3-2016).

${ }^{28}$ Tradicionalmente se ha conocido la autoría de Guzmán por obras impresas como la del hermano Parra y Cote, donde ha bebido la historiografía. El estudio más reciente al respecto es GARCÍA ZAPATA, Ignacio José: "El tabernáculo de la urna de San Juan de Dios en Granada, obra del platero Miguel de Guzmán", Laboratorio de Arte, 28, 2016, pp. 319-333.

${ }_{29}$ Agradecemos a la restauradora doña Esther Cruz su dedicado trabajo y al padre fray Juan José Hernández O.H., rector de la basílica, su colaboración en la recuperación de esta importante pieza.

${ }^{30}$ Sobre la obra de este artista véase LÓPEZ SALAMANCA, Francisco: "Aproximación a la obra del retablista Francisco José Guerrero", en PALMA ROBLES, Luis Fernando (coord.): Jornadas de Historia de Lucena. Lucena, 2007, pp. 157-184. 
Anterior en el tiempo es sin embargo el cuadro de la Virgen de Guadalupe, pintura que responde a la tipología de "copia fiel" orlada con la composición tetraepisódica de las apariciones. Su datación puede estimarse con bastante precisión en base a dos elementos que aparecen en la pintura: la descripción visual del santuario del Tepeyac del óvalo central, y la presencia de ángeles músicos en los óvalos esquineros que derivan de los grabados ideados en 1685 por el burilista Matías de Arteaga y Alfaro ${ }^{31}$. Este paréntesis temporal nos sitúa la obra entre los años 1690 y 1695 , siendo muy probablemente de algún pintor del círculo de los Arellano (Figura 6).

Según la teoría que ahora proponemos, el retablo de la Virgen de Guadalupe era usado por fray Alonso de Jesús y Ortega para presidir su pequeño oratorio privado ${ }^{32}$, ubicado en su celda del claustro bajo del convento. Las mediciones realizadas in situ certifican la correspondencia entre el mueble barroco y el hueco disponible en la pared del antiguo oratorio ${ }^{33}$. Según consta, las obras de la celda general se acabaron el 4 de febrero de $1740^{34}$ y al año siguiente, su reverendísima obtuvo permiso del papa para "que todos los Generales, y Ex Generales de nuestra Religion, pudiessen tener Oratorio privado cada uno en los Lugares de sus residencias" ${ }^{35}$. Este debió ser el momento en el que Guerrero ejecutara la hechura del mueble, el cual está en perfecta sintonía con las decoraciones existentes en la cúpula de aquella estancia.

La humildad de este pequeño retablo granadino queda desbordada por su alto valor simbólico, pues en él se manifiesta lo que podríamos llamar la "sintonía de los tiempos". El padre Ortega fue proclamado general perpetuo de la orden en 1757 por parte del papa Benedicto XIV, quien, no lo olvidemos, fue el mismo pontífice que tres años antes, en 1754, había emitido la bula Non est equidem

${ }^{31}$ Estos grabados acompañaban la obra Felicidad de México de Becerra Tanco. Fueron publicados por primera vez en CUADRIELLO, Jaime: Maravilla Americana. Variantes de la iconografía guadalupana. Siglos XVII-XIX. Guadalajara, 1989, p. 47; siendo el estudio más reciente al respecto MONTES GONZÁLEZ, Francisco: Sevilla guadalupana. Arte, historia y devoción. Sevilla, 2015, pp. 100-103.

${ }^{32}$ Isla Mingorance ya sugirió que el retablo fue propiedad del padre Ortega aunque sin explicar sus argumentos ni precisar el origen mexicano de la obra, su cronología o posible autor. Véase ISLA MINGORANCE, Encarnación: Hospital y Basílica de San Juan de Dios en Granada. León, 1979, p. 19.

${ }^{33}$ Tras la exclaustración de los frailes juaninos, el convento pasó a tener varios usos hasta que se convirtió en hospital civil provincial. En ese momento la celda completa del padre Ortega se adaptó para capilla de enfermos eliminándose la distribución interior, aunque, por suerte, el pequeño espacio de su oratorio fue respetado al usarse como sacristía.

${ }^{34}$ ADPG, leg. 25, n. 11, 1758, Imbentario de las alaxas de Iglesia, Sachristia, y Camarin que N. Rmo. P. Gral. entregò a este convento de Granada, f. $52 \mathrm{r}$.

${ }^{35}$ DE LA PEÑA, Bartolomé: Certificación..., op. cit., p. 45. 
declarando a la Virgen de Guadalupe patrona de la Nueva España. Así, en el altar juanino se dan cita varios de los rumbos religiosos y artísticos más significativos de la época: el culto y la difusión emergente de la imagen guadalupana, el general perpetuo de la Orden Hospitalaria con casas abiertas en buena parte de América y el papa de grato recuerdo que reconoce oficialmente a una y a otro. Todo ello podríamos completarlo además con el feliz maridaje que supone la interacción de los artistas andaluces Francisco Guerrero y Diego Sánchez Sarabia y del anónimo artista del círculo de los Arellano. Sin aparente relación entre sí, estos artistas barrocos aparecen unidos aquí para ilustrar, una vez más, los nexos culturales existentes entre Andalucía y América.

Pero continuemos con nuestro análisis. En el circuito del camarín de San Juan de Dios se encuentran otras obras venidas por o desde América, las cuales están incluidas en la idea general que subyace en todo el conjunto: la del orbe cristiano adorando la santidad de Juan de Dios. La obra se hizo a todo lujo. Elementos de toda la cristiandad, y más allá, se importaron sin reparar en estilos o distancias. Los mármoles fueron extraídos de Sierra Elvira, Cabra, Sierra Nevada y Macael, los chapiteles de las torres fueron hechos "à la moda de los de Madrid" 36 -para lo que se trajo a un maestro desde la Corte-, los niños de vestir vinieron de Nápoles, el terno rico de Génova y grandes partidas de pintura, urnas de bronce y relicarios arribaron desde Roma. Completando este panorama, las Indias Orientales aportaron algunas preseas que responden al gusto dieciochesco por las chinerías. Estas apetecidas mercaderías llegaban a España a través del Galeón de Manila después de una larga ruta que atravesaba el Pacífico y fondeaba "en Acapulco donde asistía a la feria comercial. Después, el cargamento aumentado llegaba por tierra hasta Veracrúz, desde donde la nave de Acapulco se dirigía a Cádiz" ${ }^{37}$. Dos de estas piezas asiáticas llegadas en la Nao de China son los tibores del antecamarín (Figura 7), los cuales ya se encontraban prevenidos en Granada en 1746: "Ay dos Tibores de China, à modo de tinajitas, de mas de cinco quartas de alto para el Camarin en haziendoles su pie"38. Las piezas quedaron instaladas en el emplazamiento que aún mantienen según consta en los diferentes documentos que conservamos, desde la crónica de la inauguración del templo ${ }^{39}$ hasta los diferentes inventarios de los siglos XIX y $\mathrm{XX}^{40}$. Sus soportes tallados en madera presentan

36 PARRA Y COTE, Fray Alonso: Desempeño el mas honroso..., op. cit., p. 205.

${ }^{37}$ GARCÍA-ORMAECHEA Y QUERO, Carmen: Porcelana china en España. Tesis doctoral. Madrid, 1987, p. 460. En el mismo sentido RUIZ GUTIÉRREZ, Ana: El Galeón de Manila (1565-1815). Intercambios culturales. Granada, 2016, pp. 49-54.

${ }^{38}$ DE LA PEÑA, Bartolomé: Certificación..., op. cit., p. 44.

39 PARRA Y COTE, Fray Alonso: Desempeño el mas honroso..., op. cit., p. 250.

${ }^{40}$ Por ejemplo en ABSJD (Archivo de la Basílica de San Juan de Dios), doc. 21/17, 1830, Inventario que ago yo Fr. Antonio Morales como Sacristan Mayor de este Primitivo convento orden de n. P. S. Juan de Dios, al M. R. P. Prior y Provincial fr. Salbador de Castro, 
motivos antropomorfos muy parecidos a los que hay en las embocaduras de la sacristía, pero con un matiz, la piel de estos personajes está laminada en pan de plata -hoy muy ennegrecida por la oxidación-.

Los tibores presentan un perfil abalaustrado y decreciente hacia la base, siendo los hombros altos y redondeados, y el cuello, corto y ancho. La tapadera es de tipo cupuliforme con ala y asidero de forma esférica -o capullo de flor de loto-. El tipo de esmalte presente en estas porcelanas es el que los expertos clasifican como Famille Verte ${ }^{41}$, siendo sus motivos florales peonías que se destacan en rojo de hierro y dorado. Se pueden datar en el periodo de la dinastía Qing (1644-1911), y más concretamente en el reinado del emperador Quianlong (17351796 ${ }^{42}$. Ambos tibores están fracturados, quedando constancia de que en 1892 "se trató de arreglar un jarrón de China que fue hecho pedazos en la antesala del Camarin por haberse desprendido" un adorno de la sala, arreglándose al mes siguiente tras la aprobación en el capítulo de septiembre ${ }^{43}$.

En la misma estancia donde se encuentran los tibores, hay dos idolillos chinos con forma animal que flanquean la entrada al camarín de las reliquias (Figura 8). Son descritos por Parra y Cote como "dos Perritos muy al natural, siendo lo mas singular, que el todo de su formacion es executado con variedad de preciosas conchas, y caracolitos de Mar" ${ }^{\prime 4}$. El inventario de 1772 consigna estas piezas de la siguiente manera: "hay otras dos [urnas] mas pequeñas talladas y doradas con sus cristales y en cada una un perrico de conchas y caracolas yndianos y otras figuras de china que le acompañan" ${ }^{45}$, lo cual quiere decir que ambos escaparates contaban con otras chucherías orientales que se perdieron antes de $1830^{46}$.

de todas las cosas pertenecientes a Iglesia y Sacristía. Asimismo aparecen en los inventarios de 1908, 1922, 1925, 1934, 1940 y 1946, conservados en el mismo archivo.

${ }^{41}$ Término establecido por la historiografía francesa desde el siglo XIX cuya traducción al español es "familia verde". Véase JACQUEMART, Albert y LE BLANT, Edmond: Histoire artistique, industrielle et comercielle de la Porcelaine. París, 1862.

${ }^{42}$ Piezas similares han sido catalogadas en KRAHL, Regina: Chinese Ceramics from the Meiyintang Collection. Vol. II. Londres, 1994.

43 AMSJD, Ar. VI, Libro primero de Capítulos Locales Granada 1879-1922, 31-81892, Libro donde se anotan las determinaciones de los Capitulos conventuales y los decretos y órdenes dadas por el General o Provincial en sus visitas, f. 23v.

44 PARRA Y COTE, Fray Alonso: Desempeño el mas honroso..., op. cit., p. 249.

${ }^{45}$ ADPG, San Juan de Dios Gobierno, Actas, L07877, 3-5-1772, Libro de inventario de los bienes del Hospital y Convento de San Juan de Dios 1772-1796, s. f.

${ }^{46}$ Inventarios posteriores solo describen las figuras principales. En el de 1830 se habla de "perro y perra; formados de conchas y caracolas de Yndias", en otro posterior que carece de fecha se consignan como "ídolos japoneses" y en el de 1922 se vuelve a retomar lo de "Idolos Americanos". Aunque observamos un cierto titubeo en la documentación, todos estos testimonios de los siglos XIX y XX apuntan a una tradición oral que sin duda conocía el trasiego transatlántico de las piezas. Cfr. ABSJD, doc. 21/17, 1830, Inventario 
El interés cortesano por este tipo de figuras a medio camino entre lo exótico y su consideración de amuletos guardianes lo podemos rastrear en muchos documentos de época barroca, siendo ejemplo de ello una recepción de dote fechada en 8 de febrero de 1685 en El Puerto de Santa María, donde se menciona "una pareja de leoncitos de la china dorados" $" 47$. En la misma línea se sitúa la partición de bienes de don Juan Antonio de Reynoso y Mendoza - a la sazón uno de los comerciantes más importantes de El Puerto de Santa María- hecha en 1725, donde se da cuenta de que poseía "dos leoncitos de china"48 entre gran cantidad de objetos procedentes de Indias.

Pero volviendo a los que se conservan en San Juan de Dios, estos ejemplares tienen valor de exclusividad por dos motivos: presentar la rareza de encontrarse en un conjunto eclesiástico -conservando además su lugar original-, y estar hechos con caracolas marinas en lugar de en porcelana o metal. En cuanto a su significado original, no se trata de una pareja de los típicos leones chinos o "Leones de Fu", asociados a la vigilancia y la defensa, sino que su identidad habría que buscarla más bien en ciertos animales mitológicos de la cultura china como Qilin o Pixiu. La diferencia a nivel de representación formal estriba en que estas últimas criaturas son de carácter híbrido, pues combinan partes de diferentes animales $^{49}$. Los ejemplares existentes en Granada se corresponden con el Pixiu (en chino: 貔㹯), especie de león alado que está considerado en la mitología china como un animal devorador de oro, plata y joyas, siendo tradicionalmente usado dentro del feng shui para atraer la riqueza en el hogar. Aunque nuestros animales carecen de alas, no hay duda de esta identidad ya que los genitales de ambas piezas aparecen detallados, uno en sentido masculino y otro en sentido femenino, lo que está en relación a los dos géneros de Pixiu existentes: el macho o "Tiān lù" que se distingue por ser unicornio, y la hembra o "Bìxié" que presenta doble asta

que ago yo Fr. Antonio Morales como Sacristan Mayor de este Primitivo convento orden de n. P. S. Juan de Dios, al M. R. P. Prior y Provincial fr. Salbador de Castro, de todas las cosas pertenecientes a Iglesia y Sacristía, f. 17r; ABSJD, sin clasificación, documento anterior a 1908 sin fecha, Inventario de la Iglesia y Camarin de nuestro Padre San Juan de Dios y del Hospital del Arcangel San Rafael. Granada, f. 10v; y ABSJD, sin clasificación, 1922, Inventario del Asilo de S. Rafael de Granada, f. 6v.

47 AHPC (Archivo Histórico Provincial de Cádiz), Protocolos de El Puerto de Santa María, Protocolos, oficio n ${ }^{\circ}$ 1, notario Francisco Álvarez, Recepción de dote de Ana María de Guzmán, 8-2-1685, f. 112v.

48 AHPC, Protocolos de El Puerto de Santa María, oficio $n^{\circ} 5$, notario Antonio Jiménez, 1725, Partición de bienes de don Juan Antonio de Reynoso y Mendoza, ff. 234r-ss.

49 TAO, Lili: “麒麟形象考述” (The Imagen of Unicorn), 白城师范学院学报 (Journal of Baicheng Normal College), 20, 2, 2006, pp. 71-73; y WANG, Yan: “貔㤥吉祥文化刍议” (The Auspicious Culture of Pixiu), 文学界. 理论版 (Literatures. Theory Edition), 4, 2011, pp. 286-287. Agradecemos a doña Meng Zhou la traducción de las fuentes bibliográficas chinas utilizadas en este trabajo. 
sobre su cabeza ${ }^{50}$. No sabemos si el padre Ortega fue consciente de la simbología exacta de estos animales mitológicos, pero algún conocimiento debió de tener al respecto cuando los colocó custodiando la puerta de entrada al camarín, verdadero Sancta Sanctorum del templo. Así es como suelen aparecer en China, en pareja, enfrentados y flanqueando vanos de entrada a diferentes recintos sagrados, ya que son considerados símbolos de suerte y prosperidad.

Finalmente, una vez que hemos glosados los principales tesoros transatlánticos llegados a Granada durante el mandato del padre Ortega, creemos preciso llamar la atención sobre otros elementos de origen americano que si bien son más prosaicos en su naturaleza, tuvieron un gran valor simbólico o social. Así, la ornamentación barroca de la basílica de San Juan de Dios de Granada no podría ser entendida sin considerar la reiterada aparición de la patata como motivo ornamental, especie vegetal que llegaría de América para revolucionar la gastronomía europea. La flor de este tubérculo aparece tanto en las pinturas murales de Tomás Ferrer como en los elementos de madera tallados por Francisco Guerrero, desde el cancel de entrada del templo hasta las cajoneras de la sacristía. Otro elemento gastronómico proveniente de América fue el chocolate, producto muy valorado por las clases altas de la sociedad que acostumbraban a tomarlo en recipientes de loza china. Pues bien, tenemos conocimiento de que este preciado manjar también estuvo presente en la mesa del padre Ortega, quien lo servía en su celda para agasajar a los religiosos del convento que lo visitaban ${ }^{51}$.

\section{CONCLUSIONES}

Una primera reflexión de importancia es la que tiene que ver con la esfera del poder y las redes de contactos en la Edad Moderna. La historia constructiva del templo de San Juan de Dios es un elocuente testimonio de cómo se relacionaban entre sí algunos de los personajes más influyentes del momento, desde el rey y el papa, hasta el general de una de las órdenes religiosas más importantes del momento y sus frailes subalternos. En buena medida esta capacidad para relacionarse fue lo que posibilitó que fray Alonso de Jesús y Ortega culminara con éxito su magno proyecto constructivo al tiempo que se perpetuaba de forma vitalicia como general de la orden hospitalaria.

En la consecución de estos objetivos jugó un papel fundamental la interdependencia establecida entre la casa matriz de Granada y los diferentes conventos americanos de la orden. Las contribuciones económicas y ornamentales llegadas en los galeones españoles, tanto de América como de Asia, fueron decisivas.

${ }^{50}$ QI, Xu y YUAN, Ping: “中国传统貔椨造型的文化寓意解析” (Analysis of the Cultural Implication of Pixiu's Traditional Forms), 重庆大学学报. 社会科学版 (Journal of Chongqing University. Social Science Edition), 15, 6, 2009, pp. 119-124.

${ }^{51}$ DE LA PEÑA, Bartolomé: Certificación..., op. cit., p. 30. 
Sin estas aportaciones no se puede entender que, por ejemplo, haya dos animales mitológicos chinos custodiando la tumba de San Juan de Dios. El análisis de todos estos elementos foráneos, ponen de relieve la verdadera incidencia que tuvo el tráfico transatlántico en Granada, cuestión que en buena medida aún está por explorar.

En otro orden de cosas, la investigación realizada ha conllevado la identificación, restauración y puesta en valor del retablo que presidía el oratorio personal del padre Ortega. Comprobar que tan alto prelado rezaba en la intimidad de su celda ante la Virgen de Guadalupe de México, advocación más potente que nos legó el mundo americano, vuelve a ilustrarnos sobre los caminos culturales de ida y vuelta que se produjeron tras la conquista de América.

Por todo lo dicho hasta aquí, queremos reivindicar el papel jugado por el continente americano en la génesis de uno de los monumentos granadinos más importantes: la basílica de San Juan de Dios.

Fecha de recepción: 29 de octubre de 2018

Fecha de aceptación: 5 de febrero de 2019 


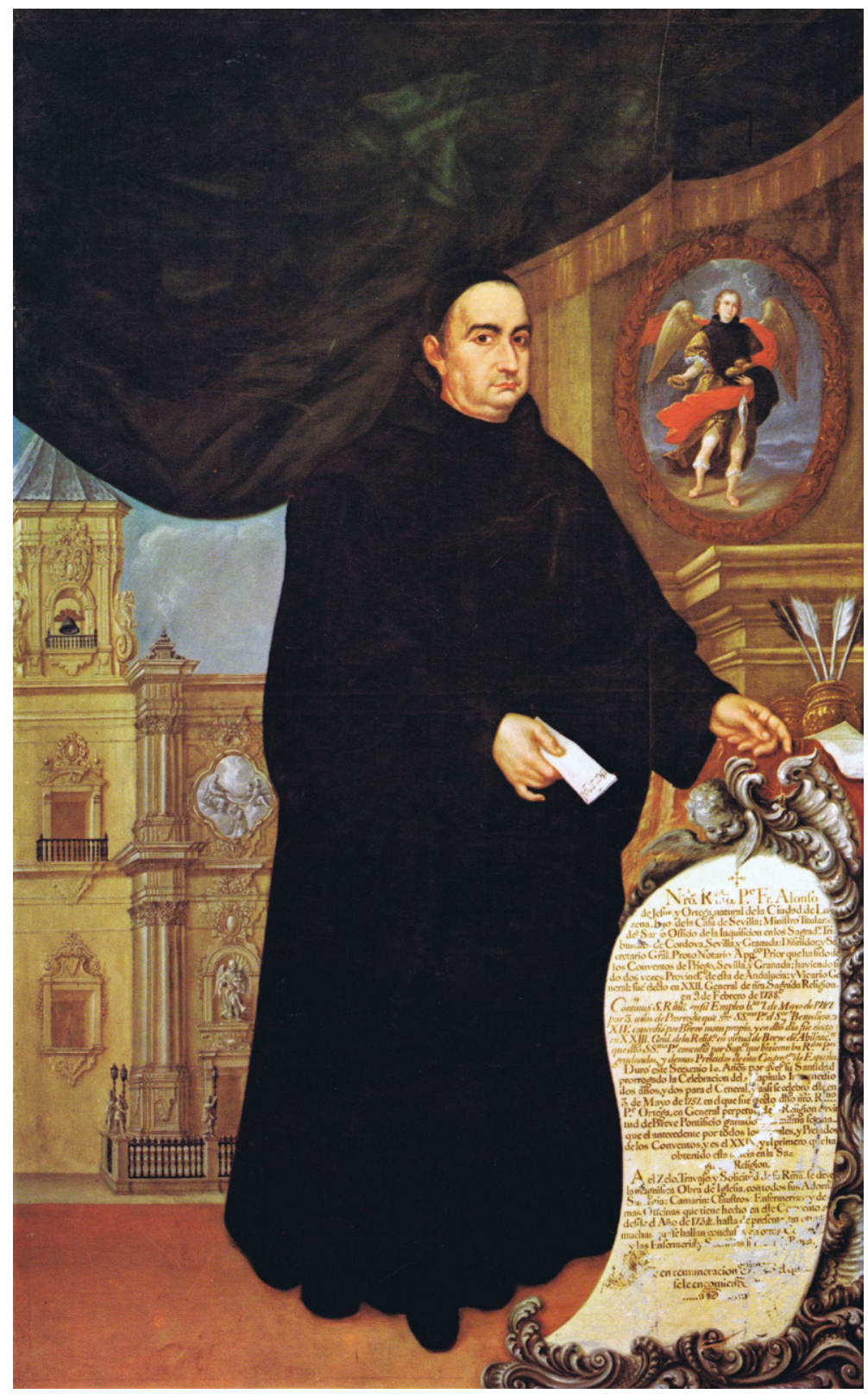

Figura 1. Diego Sánchez Sarabia, Retrato de fray Alonso de Jesús y Ortega, 1758, basílica de San Juan de Dios, Granada. 


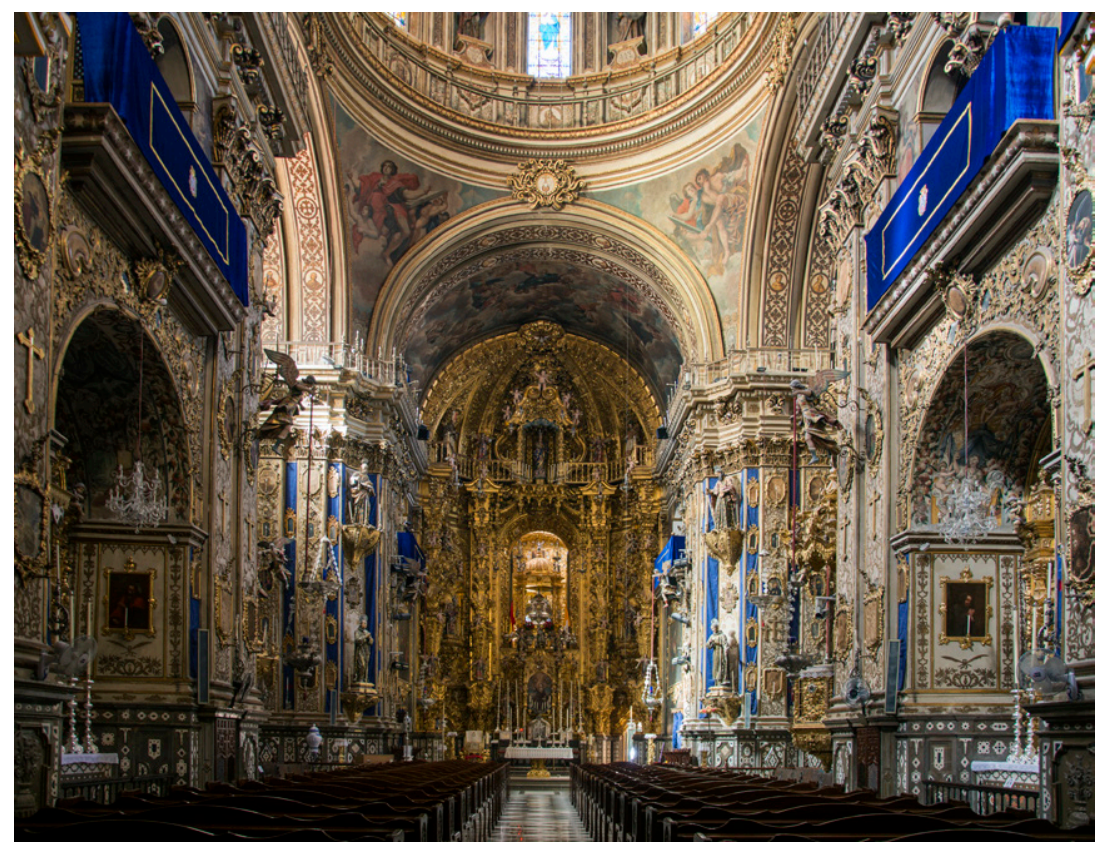

Figura 2. José de Bada y Navajas, Basílica de San Juan de Dios, 1734-1759, Granada.

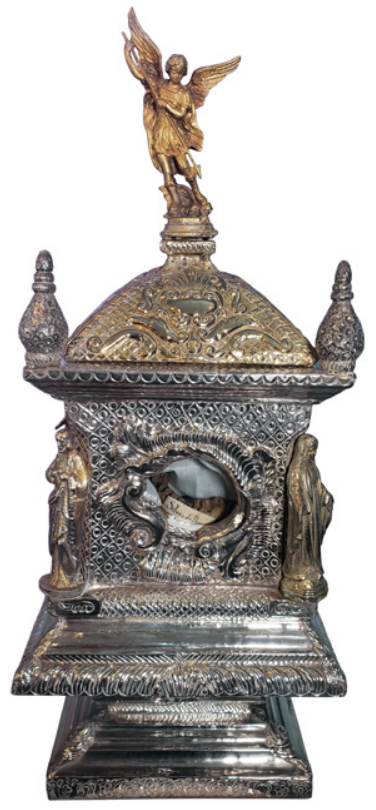

Figura 3. Reliquia de la mandíbula de San Juan de Dios de Lima. El relicario que la contiene imita en su hechura a la urna de Granada. 


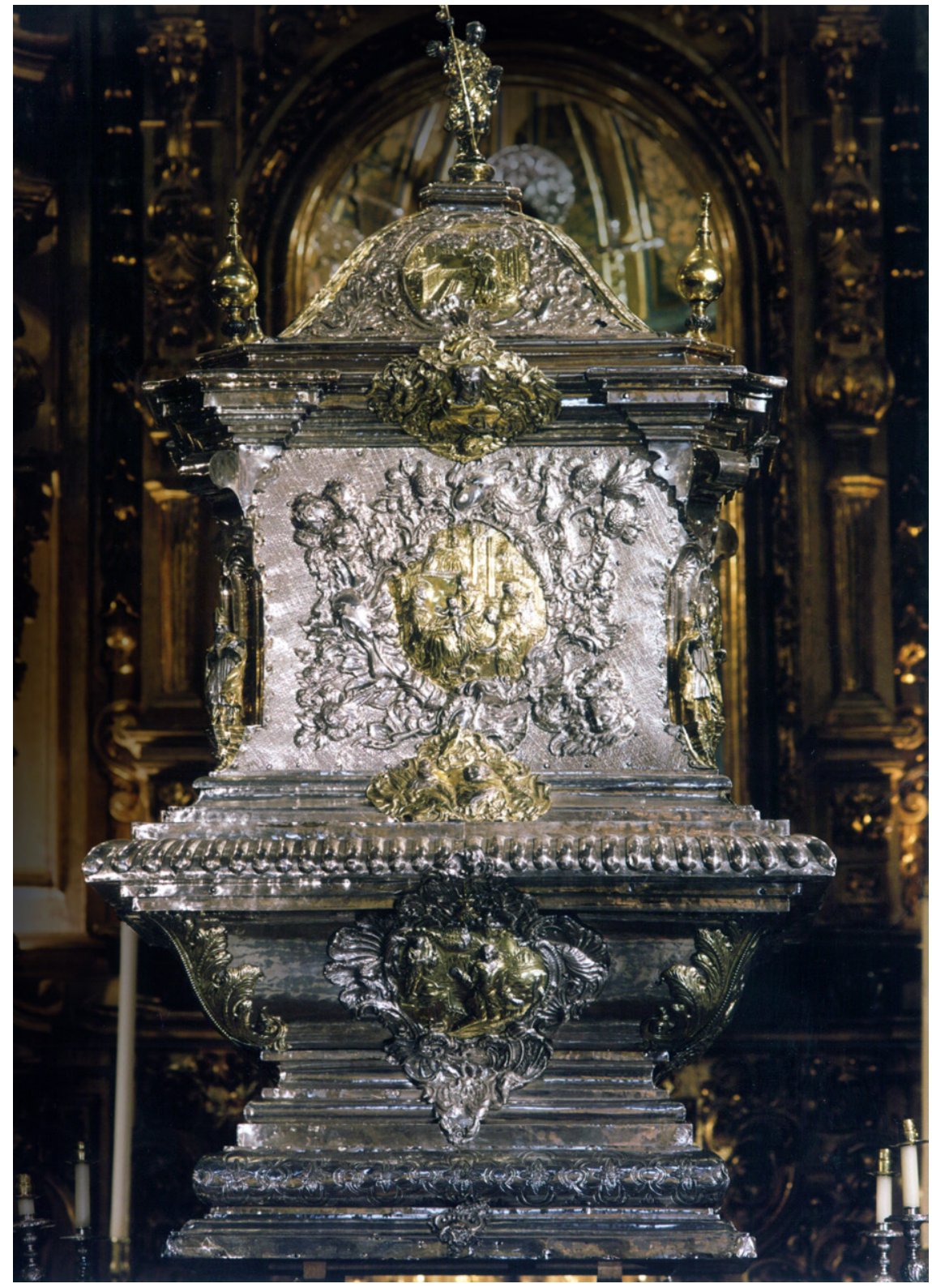

Figura 4. Miguel de Guzmán, Urna de los reliquias de San Juan de Dios, 1755, basílica de San Juan de Dios, Granada. 

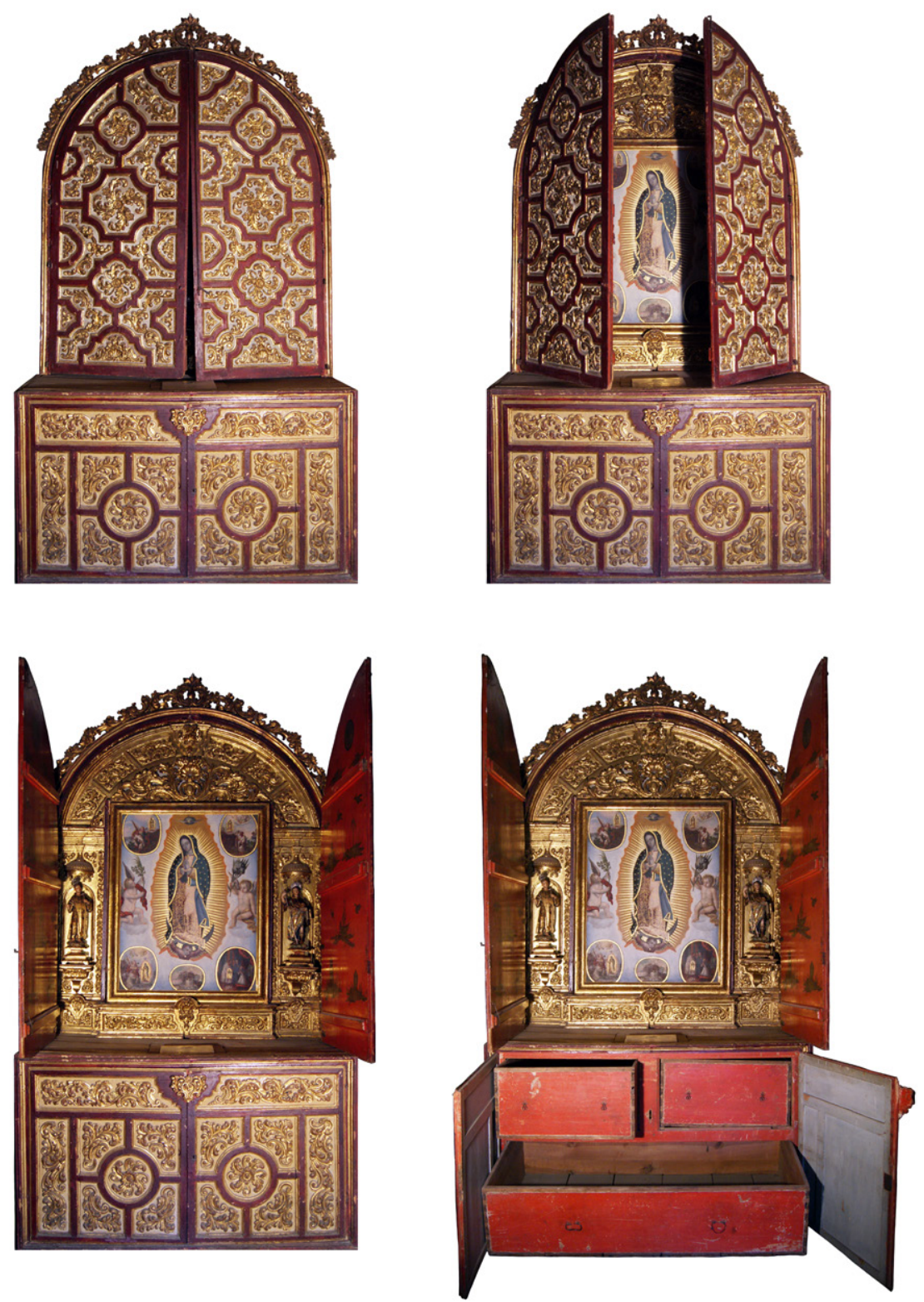

Figura 5. Francisco José Guerrero, Retablo de la Virgen de Guadalupe, hacia 1741, basílica de San Juan de Dios, Granada. 


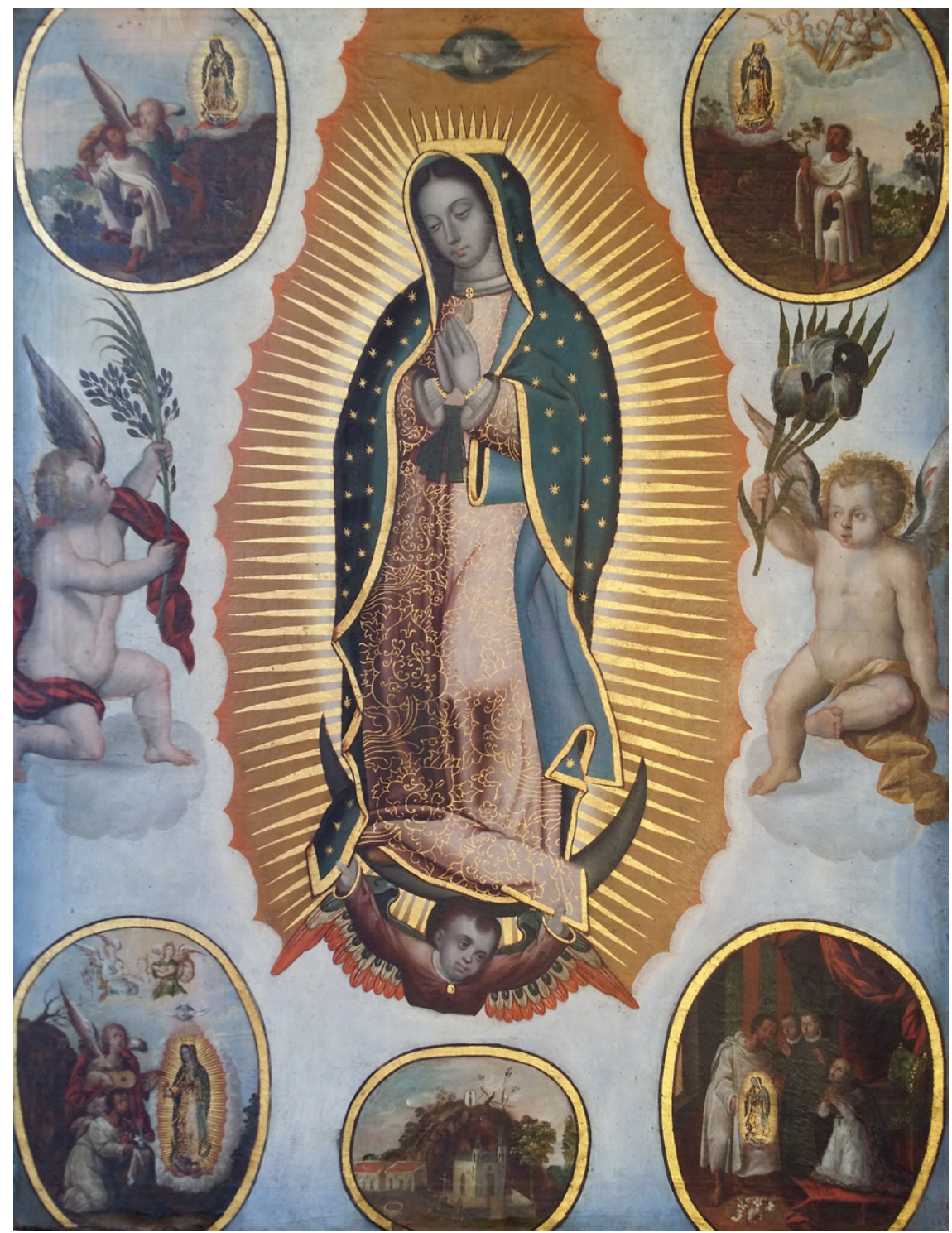

Figura 6. Círculo de los Arellano, Virgen de Guadalupe, entre 1690-1695, basílica de San Juan de Dios, Granada. 


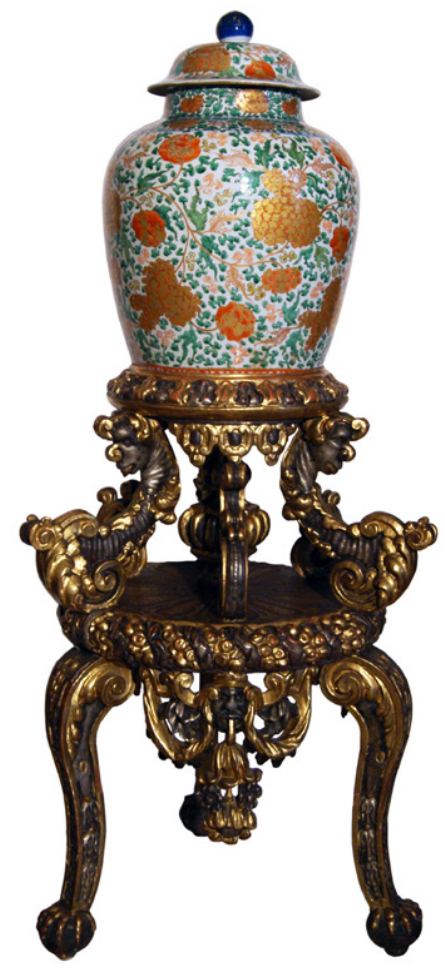

Figura 7. Obrador chino, Tibor, dinastía Qing, reinado del emperador Quianlong, entre 1735-1746, basílica de San Juan de Dios, Granada.
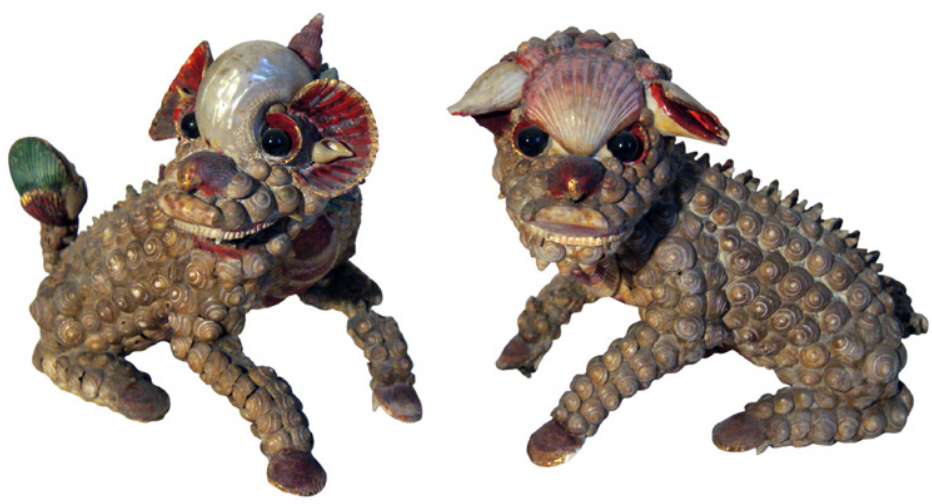

Figura 8. Obrador chino, Tiān lù y Bìxié, entre 1746-1759, basílica de San Juan de Dios, Granada. 